\title{
Social Justice in Control Systems Engineering
}

\section{Dr. Kathryn Johnson, Colorado School of Mines}

Kathryn Johnson is an Associate Professor at the Colorado School of Mines in the Department of Electrical Engineering and Computer Science and is Jointly Appointed at the National Renewable Energy Laboratory's National Wind Technology Center. In the fall 2011, she was a visiting researcher at Aalborg University in Denmark, where she collaborated on wind turbine control research and experienced Aalborg's Problem-Based Learning method. She has researched wind turbine control systems since 2002, with numerous projects related to reducing turbine loads and increasing energy capture. She has applied experiential learning techniques in several wind energy and control systems classes and began engineering education research related to social justice in control systems engineering in fall 2014.

\section{Dr. Jon A. Leydens, Colorado School of Mines}

Jon A. Leydens is an associate professor in the Division of Liberal Arts and International Studies at the Colorado School of Mines, USA, where he has been since 1997. Research and teaching interests include communication, social justice, and engineering education.

\section{Dr. Barbara M. Moskal, Colorado School of Mines}

Dr. Barbara Moskal is a Professor of Applied Mathematics and Statistics and the Director of the Trefny Institute for Educational Innovation at the Colorado School of Mines. She is also a senior associate editor of the Journal for Engineering Education. Her research interests include: measurement, assessment, outreach, and diversity.

\section{Ms. Deborath Silva, Colorado School of Mines}

Deborah Silva is a Graduate Research Assistant at the Colorado School of Mines. She is pursuing a M.S. in Electrical Engineering with interests in social justice applied to control systems engineering

\section{Mr. Justin Stephen Fantasky, Colorado School of Mines}

Justin Fantasky is an Undergraduate Research Assistant at the Colorado School of Mines. He is pursing a degree in Mechanical Engineering with a minor in Economics and Business with an expected graduation date of May 2016. 


\title{
Social Justice in Control Systems Engineering
}

\begin{abstract}
$\underline{\text { Abstract }}$
What occurs when social justice dimensions are integrated into a feedback control systems class, and what impacts does such integration have on student interest and motivation? Social justice defies a universal definition, but is related to the vision that people and communities have the right to equality (in various senses), to health, to dignity, and to opportunities. Social elements such as social justice may not be perceived as "engineering" by faculty and students, leading to an engineering workforce poorly trained in dealing with the social dimensions of sustainable engineering solutions. This important concept currently receives little attention within the standard engineering curricula, particularly within the engineering sciences.
\end{abstract}

The pilot-study research presented in this article uses a mixed-methods approach to assess the state of social justice awareness of students as they enter an "Introduction to Feedback Control Systems" (IFCS) class. Social justice interventions are integrated to support students as they learn about the inherent, yet often invisible, connections between social justice and control systems engineering. Instruments, such as surveys and focus groups, were used to measure the impact of the social justice interventions. The results and findings from these analyses, considering both the section with interventions and a non-intervention section of the course, are reported here. This analysis supports that participants have had some exposure to social justice but struggle to place it within the context of technical engineering science core courses. However, the participants also provided feedback on specific mechanisms for integrating social justice dimensions within IFCS that are likely to promote future student learning.

\section{Introduction}

The importance of including social justice in engineering course work is increasing as the engineering profession continues to globalize. As the world becomes electronically interconnected, engineering decisions are more frequently being made from outside of the local and global communities that they affect. Unintended consequences often result. One well-known and extreme example of an unintended consequence of engineering, which resulted from the combined marvels of the industrial revolution, is anthropogenic climate change. Engineers today struggle with climate change more than 130 years after the start of that revolution. None of the original decision makers are alive to assist in the solution process; most likely, none anticipated the problems that would result. Learning from the past, it is imperative that future engineers recognize that their designs can have both positive and negative consequences on the communities that they are designed to serve, locally and globally. Thus, engineers must develop critical thinking skills concerning the broader social impacts of their activities and an understanding of social justice implications. Since many engineers end their formal education after a bachelor's degree, such skills should be cultivated as early as possible, preferably in undergraduate education.

Social justice in engineering relates to the recognition and consideration of the impacts of engineering decisions on a broad range of communities. Elements that are commonly referenced as contributing to social justice are displayed in Figure 1. As a concept, social justice resists a 
concise definition; the discussion of its meaning encompasses a full chapter in Riley's Engineering and Social Justice [1]. Engineering for social justice, rather than simply applying a traditional design to different demographic groups, requires that engineers question foundational paradigms. Socially just engineering acknowledges and seeks to compensate for the real impacts of systemic inequalities of power on engineered systems. In [2], Winner provides many examples of technological solutions and their social justice implications. One example is modern agricultural machinery. Advanced control systems have made many crops more affordable. These same systems have reduced the sustainability of the family farm, significantly changing the agricultural lifestyle, which has had far-reaching implications on rural communities and their economies. Thus, for engineering practice, a social justice framework encourages exploration of the following questions: In the short and long-term, from engineering designs, models, and other interventions, who benefits? Who does not benefit? Who suffers?

Engineers are increasingly recognizing the need to effectively engage communities [3] in the development of designs. A social justice framework provides a foundation for democratic, participatory, effective, and sustainable community engagement by accentuating an oftenmissing dimension in engineering contexts: community agency. As faculty and students try to develop solutions in programs such as Engineers Without Borders, they should consider the priorities of the community that they will serve. Similarly, as practicing engineers develop their solutions, the impacted communities should have a voice in the solution process. Education for social justice explicitly establishes terms of societal and community engagement by calling for an aspirational ideal involving "full and equal participation of all groups in a society that is mutually shaped to meet their needs" [4] (p. 1). The process used to achieve this ideal is "democratic and participatory, inclusive and affirming of human agency and human capacities for working collaboratively to create change” [4] (p. 3).

In a traditional classroom, students are provided with a problem and are asked to find a solution. Void of the larger context, they do not have the opportunity to evaluate whether their proposed design will have a positive or negative impact on the population that it is designed to serve. Most engineering faculty members have not received formal training in social justice, leaving them equally unprepared to integrate this subject in their courses. One way to provide the larger context involves framing problems in terms of sustainability. Edwards [5] has argued that there are "three Es" for sustainability, an important concept in engineering: ecology/environment, economy/employment, and equity/equality. The first two of these concepts, ecology/environment and economy/employment, are traditionally taught as part of undergraduate engineering curriculum. Equity/equality is often missing. This study seeks to create the foundation necessary for designing and implementing effective social justice instruction within the undergraduate

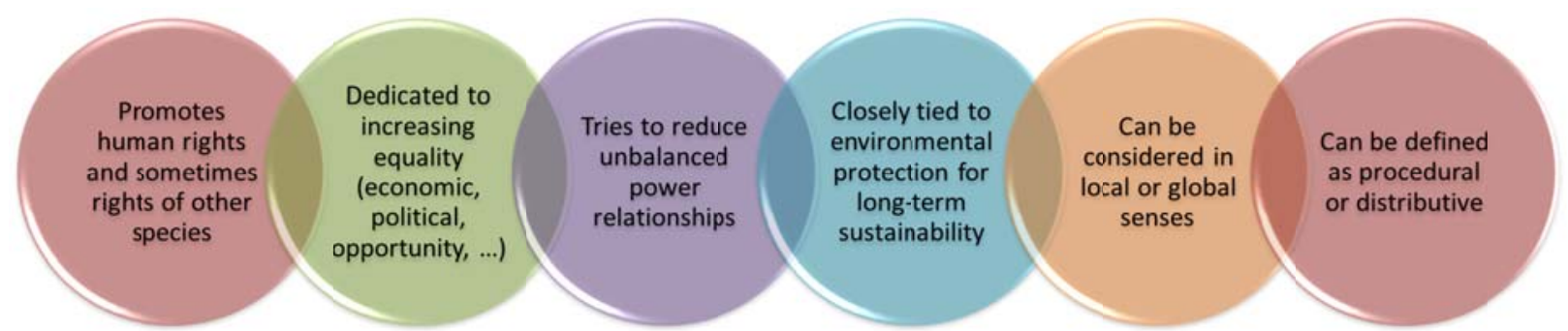

Figure 1. Elements of social justice. Although there is no single definition of the term, most definitions draw upon some of the concepts illustrated here. 
engineering curricula at one university. If social justice content appears only in humanities and social science courses for engineers, students are likely to perceive it as anywhere from irrelevant to only slightly important to engineering practice. Placing these concepts within design courses may improve its status; however, since engineering students create a hierarchy of knowledge, with engineering science comprising the top, design courses in the middle, and finally, humanities and social science courses at the bottom [6], design courses may be insufficient to raise the status compared to engineering science courses. As is argued here, social justice needs to be reinforced throughout the engineering curricula so that it receives appropriate attention in the engineering process.

\section{Background: Social Justice in Engineering}

In an overview of social justice within engineering [7], Cech argues that engineers have been poorly prepared to consider social justice because they have been incorrectly taught that technical work, which includes engineering, is apolitical or politically neutral. Most studentsand even some faculty and practicing engineers - do not understand that maintaining the status quo through their actions as an engineer is a political activity. Instructors who regard social justice as a political intrusion are perpetuating the status quo. Also, according to Cech, the meritocracy ideology, or the belief that inequality is a result of hard work alone, "legitimizes social injustices and undermines the motivation to rectify such inequalities” (p. 67). Engineering as a profession benefits from the meritocracy ideology in that it is well respected and its practitioners are typically well-compensated when compared to the average U.S. worker. Riley, in Engineering and Social Justice [1], describes how many engineers work within a system without consideration of the potential for changing or even questioning the social constructs of that system, even when social changes offer the potential for a better outcome. Riley further notes that, historically, engineering has been a career choice that enables upward socioeconomic mobility; this may reinforced a meritocracy ideology within the profession. Cech argues that, in order to accommodate social justice education, that a "cultural space" must be created within engineering by addressing depoliticization and meritocracy.

In a discussion on diversity in engineering, Riley notes that engineering's lack of significant diversity may be reflective of fundamental issues within the profession rather than the availability and use of effective recruitment and retention tools; Lucena [8] has raised this issue as well. Concerns about diversity may at first appear to be political rather than technical in nature. Downey et al. [9] has argued that in a global world, engineers need to be able to work well with people who think differently, and diversity within the field increases the benefits that these differences offer. This mindset seems to be more comfortable to many engineers, providing a potential avenue for introducing social justice to the engineering education community.

Indicators show that engineering educators are open to re-framing their educational activities to include social justice. For example, social justice has been previously and explicitly been incorporated into a few other engineering science courses within the U.S. ([10] - [15]). Adams et al. [16] additionally provide examples of educational methods that engage engineering students in considering emotions and social factors in their work. Riley [1] notes that engineers often seek to help, and that the "helping spirit and strong work ethic are important traits for engaging in social justice work” (p. 39). Schneider, Lucena, and Leydens [17] describe the rapid growth in engineering programs that are designed to help. Unfortunately, as is argued by these authors 
[17], the very nature of many of these activities contributes to a sense within engineering that communities can be defined by what they are lacking. This attitude unintentionally lends itself to the right-or-wrong problem-solving training common in engineering education. As the authors of [17] explain, the very nature of such formulation can lead to colonialist or imperialistic relationships and continued power imbalances, detracting from rather than contributing to social justice.

Tensions may also exist between educational activities that are designed to help communities and the learning goals of the engineering curriculum. Epprecht [18] has described inherent conflicts that exist in the helpful intentions of work-study programs. The historic motivation for many of these programs is to promote capitalism and prevent communism and socialism. This goal is political in nature. Yet, many engineering students are drawn to these programs partially due to the positive impact that they will have on communities. What many students and programs do not acknowledge is that these volunteer programs can cost local workers their jobs, since work-study students offer free labor. Additionally, these programs can raise the expectations of the community, only to discover that they cannot be sustained locally once the work-study program has ended. Another concern is that often a significant portion of the funding, which is raised under the premise of supporting the target community, is directed to the work-study program. Although this investment may be necessary to support the program, it is not necessarily in the best interest of the community that it serves [18].

Related to and complementing the introduction of social justice to the engineering curriculum is the movement to embed engineering ethics in that same curriculum. Haws [19] analyzed 42 ASEE papers related to engineering ethics that were published between 1996 and 1999. Many of these articles raised questions as to why engineering ethics is important enough to demand its own field; Haws concludes that instruction in ethics alone leads engineering students to believe that ethical decisions result in right or wrong answers, as many students have learned to expect in their technical courses. This false belief is reinforced through the authoritarian nature of the Professional Engineer's Code of Ethics. Students need to learn that engineering ethics results in many "grey areas" in which a correct decision cannot be made [19]. Often, these grey areas include concerns with social justice.

Herkert has offered a framework for social justice within engineering ethics, which includes micro and macroethical considerations [20]. In particular, he notes that microethics is related to ethical decisions that individual engineers make, while macroethics is concerned with the engineering profession and its responsibility to society, especially with respect to technology. He draws a connection between macroethics and the ABET 2000 student outcome (h) that engineering education should help students to understand "the impact of engineering solutions in a global, economic, environmental, and societal context.” [21] (p. 3) This student outcome sounds much like a social justice concept, yet when contrasted with Haws's analysis, it appears to be largely overlooked within engineering ethics instruction. In fact, many of the engineering ethics case studies on the National Academy of Engineering Online Ethics Center ${ }^{1}$ lack significant connections to macroethical issues such as discrimination, sustainability, and community engagement, an issue Herkert is seeking to address. Thus, an opportunity exists to

\footnotetext{
${ }^{1}$ http://www.onlineethics.org/
} 
explore appropriate methods for embedding macroethical, social justice dimensions into the engineering education curriculum.

\section{$\underline{\text { Research Questions }}$}

This research begins to explore methodologies for embedding social justice considerations into the engineering curriculum. The subgroup of interest is primarily undergraduate students who are majoring in electrical engineering (EE) or mechanical engineering (ME) at the target institutions. The research questions that frame this investigation are as follows:

RQ1. What exposure to social justice concepts have students had in their university courses prior to taking our Introduction to Feedback Control Systems (IFCS) course, which is required for both $\mathrm{EE}$ and $\mathrm{ME}$ majors?

RQ2. How do students report their perceptions of control systems classes that explicitly include engineering and social justice units compared to similar classes that do not include social justice?

RQ3. How does targeted social justice instruction impact student plans to pursue additional control systems courses and student ability to recognize the social justice dimensions of control systems?

\section{Methodology}

This section begins with a description of the course and the participating student population. A discussion of the classroom-based social justice interventions and our data collection instruments, surveys and focus groups, follows.

\section{Course}

Two sections of the IFCS course were taught in the fall of 2014 and both were included in this investigation. IFCS is a required course that is completed in the junior or senior year by EE and ME majors. Engineering physics students may also complete this course as an elective. One section was taught without interventions (WOI); the other section was taught with interventions (WI). Fifty-one students enrolled in the WOI section and 53 students enrolled in the WI section. Different instructors taught each section of the course.

The textbook, written lecture material, most assignments, and most aspects of the final project were consistent across the two sections, though lectures differed in emphasis according to each instructor's teaching philosophy and student questions. The difference between instructors is an acknowledged limitation of this investigation. In order to partially account for instructor differences and the impact that this may have on the research results, the following methods were used: (a) confirming data was acquired across data sources and (b) questions were explicitly asked of students concerning classroom instructional techniques.

At an institutional level, the efforts to implement social justice were neither supported nor challenged. The implementation of the course change was left as a decision of the instructors. Human subjects approval was sought and secured. If the course were formally changed to include the intervention across all offered sections, we would anticipate greater scrutiny and discussion on the part of the department and institution. The investigative team will not seek this 
type of change until additional data has been collected and analyzed and found to be compelling. However, some level of support for integrating social justice was inherent in the response from the lead author's Dean, who has taught IFCS and with whom the authors have discussed the National Science Foundation grant to answer the research questions and its impacts on the course. That grant gave the pedagogical risk-taking more legitimacy and perhaps averted some suspicion.

\section{Social Justice Interventions}

One difference between the WI and WOI sections was the inclusion of the social justice intervention. The social justice intervention included several components:

1. Engineering and social justice class reading. Students who attended the WI section were assigned to read Chapter 2 of [1], "Mindsets in Engineering” to introduce them to the concept of an engineering culture. An in-class quiz on the chapter content and a brief discussion followed.

2. Guest lecture. During the sixth week of the semester, a social justice expert gave a guest lecture on the topic. This lecture listed six criteria for social justice: contextual listening, identifying structural conditions, acknowledging political agency, increasing opportunities and resources, reducing imposed risks and harms, and enhancing human capabilities that students subsequently used to evaluate social justice implications of class topics. To illustrate some of those social justice criteria, a case study of the development of an auto-adjusting insulin pump was integrated into the lecture. This lecture was designed to expand the students' understanding of social justice as a legitimate multidisciplinary field that has important implications for engineering.

3. In-class examples. The WI instructor provided numerous social-justice examples related to control systems during the semester to motivate student interest in lecture material. For instance, the lecture on step response used an automated harvesting equipment example, while a resonance example included a video of an unbalanced washing machine and discussion on safety implications. In several classes related to choosing design specifications for various applications, social implications related to the specific application were discussed and students were asked to relate qualitative social elements to quantitative specifications.

4. Homework assignments. Students were explicitly exposed to social justice through three homework assignments. For the first of these, the professor of the WI section re-wrote a problem so that it motivated social justice considerations both in the problem statement and by requiring students to consider social elements in design considerations. The WI students were assigned the re-written problem (Figure 3), while the WOI students were assigned the original (Figure 2). In a following homework assignment, WI students were provided with the original problem statement and assigned to reflect on how the problem's re-write challenged them to consider at least two of the social justice criteria presented in the guest lecture. Finally, students were assigned to re-write a class problem of their choosing to motivate social justice considerations.

5. Team projects. The final project assignment used in both the WI and WOI sections required students to work in teams to design a controller for an application of interest to the team members. In the WI section, students were required to select at least one design constraint based on social justice considerations. 
Original Problem: You are to design a Proportional/Integral (PI) control system for an tank with controllable volumetric flow input $q_{i n}$. The level of liquid in the tank must be carefully regulated.

The desired specifications are:

- Settling time equal to 10 seconds

- Overshoot of $15 \%$

- Zero steady state error for unit step reference

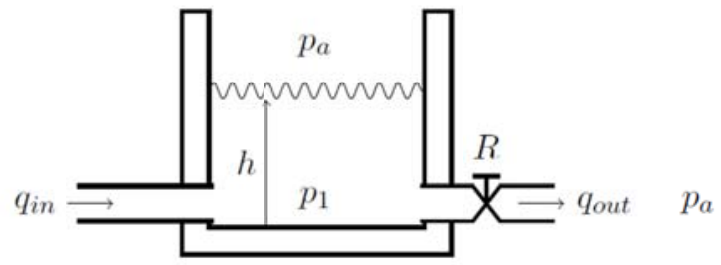

Tank Area: $A$

The tank has an area of $100 \mathrm{~m}^{2}$, the density of the liquid is such that $\rho g=10000 \mathrm{~kg} \mathrm{~m}^{-2} \mathrm{~s}^{-2}$ and the flow resistance at the outlet valve is $400 \mathrm{~kg} \mathrm{~m}^{-4} \mathrm{~s}^{-1}$.

(a) Find the transfer function for the tank from input $q_{\text {in }}$ to output $h$.

(b) Draw a block diagram that represents the PI feedback control system. Include the reference signal for the desired height $H_{d}(s)$

(c) Determine the acceptable damping ratio and undamped natural frequency of the closed loop poles achieve the desired closed loop specifications

(d) Find the gains for your controller that achieve the pole locations for part (c)

Figure 2. Original homework problem assignment.

\section{Surveys}

Students who participated in both sections of the course, WOI and WI, were invited via email to complete an online, anonymous survey before the social justice interventions were implemented in the WI class. The questions that comprised this survey are contained in the results section under "Surveys." This instrument was designed to address RQ1. Twenty-nine out of 104 students participated (10 from the WOI section and 19 from the WI section), resulting in an overall response rate of $27.8 \%$.

\section{Focus Groups}

Two focus groups were held in each section of the course. In all four groups, a total of 14 students participated. Both WI and WOI sections had one focus group that consisted of three students and another focus group that consisted of four students. Focus groups lasted approximately one hour each and were conducted by a researcher who was not teaching the section of the course in which the students were enrolled. Volunteers received a participant incentive fee in the form of a gift card. The focus groups occurred during weeks 11 and 12 of the 16-week semester.

The focus group questions varied slightly between the WI and WOI sections (See Appendices A and $\mathrm{B}$ ) and were designed to address the three research questions. The differences addressed the fact that social justice was explicitly taught in the WI class but not the WOI class. WI students were also asked explicit questions concerning social justice, whereas the WOI students were asked about the social impacts of engineering.

Focus groups were audio recorded and transcribed. Each focus group transcript was analyzed using QSR International's NVivo@ software, with a coding method focusing on themes related 


\section{Rewritten Problem (for Social Justice class):}

A remote village has won a grant to install a tank that can provide household water during the dry season. To ensure a balance between protecting the pump (extending its lifetime as long as possible), ensuring enough water for the village's needs, and not wasting water by overfilling the tank, you are asked to design a Proportional/Integral (PI) control system to control the level of liquid in the tank. Your control input is the volumetric flow input $q_{\text {in }}$ into the tank, which is shown in the figure below. The tank has an area of $100 \mathrm{~m}^{2}$, the density of the water is $\rho=1000 \mathrm{~kg} \mathrm{~m}^{-2}$, and the flow resistance at the outlet valve is $400 \mathrm{~kg} \mathrm{~m}^{-4} \mathrm{~s}^{-1}$.

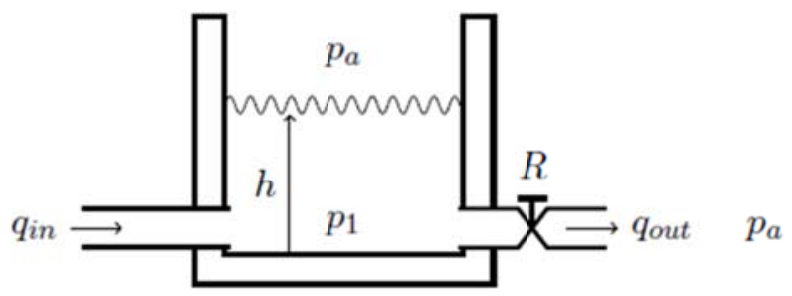

Tank Area: $A$

(a) Find the transfer function for the tank from input $q_{\text {in }}$ to output $h$.

(b) Select three design specifications for your closed-loop controller + tank system and justify them briefly in a sentence or two. At least one specification must be on a transient response parameter (rise time, settling time, or percent overshoot) and at least one must be on a steady-state characteristic (such as steady state error or disturbance rejection). Your third specification may be from transient response, steady-state response, or something else you think is important.

(c) Draw a block diagram that represents the PI feedback control system. Include the reference signal for the desired height $H_{d}(s)$. If one of your design specifications is related to disturbance rejection, you must include a disturbance.

(d) Determine the acceptable damping ratio and undamped natural frequency of the closed loop poles achieve the desired closed loop specifications.

(e) Find the gains for your controller that achieve the closed-loop pole locations to meet your design specifications.

Figure 3. Rewritten homework problem with implicit social justice dimensions.

to the research questions. To bolster inter-rater reliability, each focus group transcript was coded and analyzed by at least two members of the research team, who then compared their respective findings. These comparisons contributed to a consensus on the findings discussed below.

\section{$\underline{\text { Results and Findings }}$}

This section summarizes the results and findings by instrument. The first section addresses the survey that the students completed at the start of the course and addresses RQ1-RQ3. This is followed by a description of the responses to the focus groups and the interviews. All three research questions were addressed during the focus group and interview process.

\section{Surveys}

Complete statements of the survey questions are included in the tables that appear later in this section. The first eight survey questions were intended to provide insight into RQ1; five were 


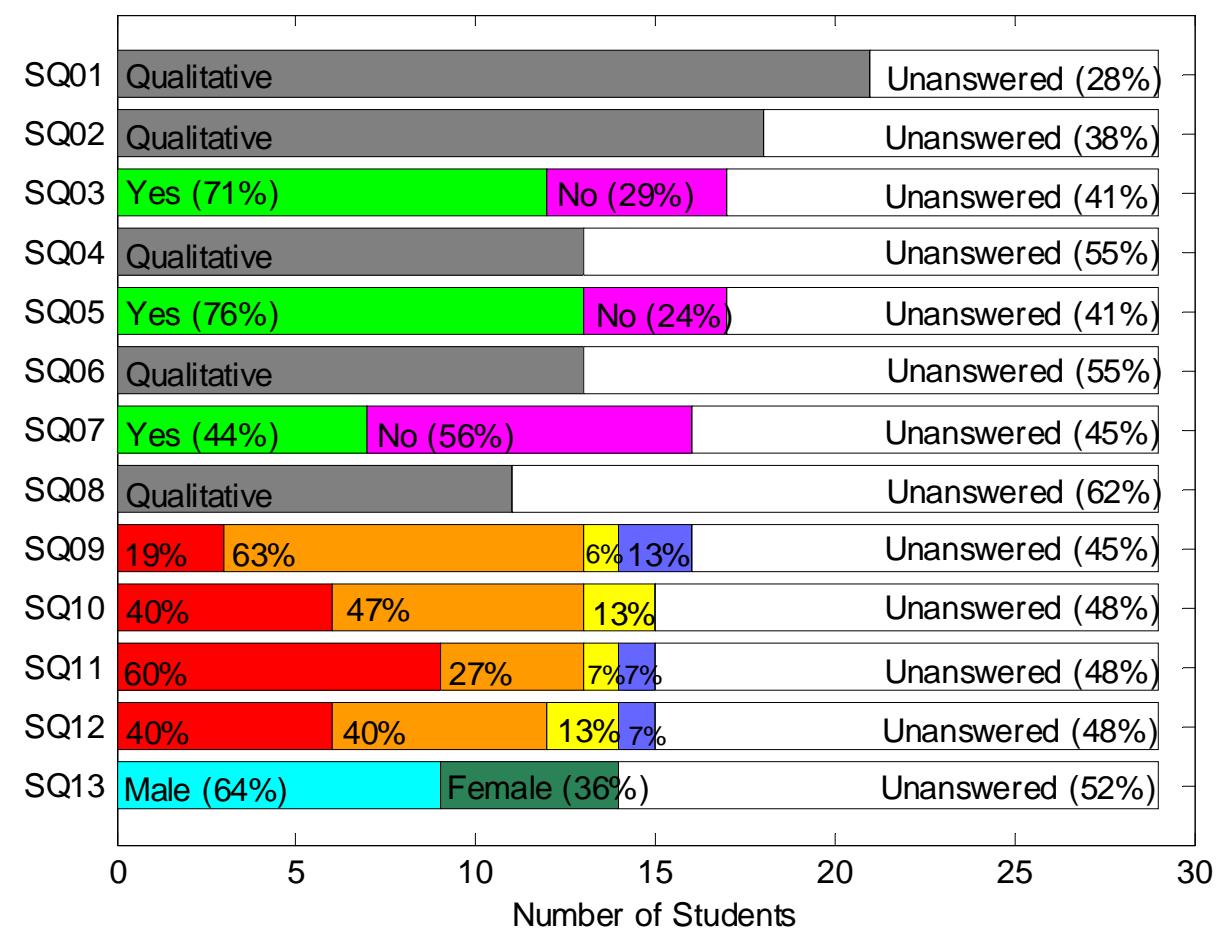

Figure 4. Summary of survey responses subdivided by type. Response percentages are based on those who provided a response for each question. For SQ9-SQ13, red is option "5" (very appropriate or very relevant) and blue is option " 1 " (very inappropriate or very irrelevant). Qualitative questions are identified here, but summarized in the text.

open-ended (1, 2, 4, 6, and 8), and the remaining three were yes/no (3, 5, and 7). The next four questions were designed to address RQ2 and RQ3 and use a Likert scale. For all survey questions except questions 4, 6 and 8, the response rate among those who took the survey ranged from $48 \%$ to $72 \%$, with the highest response rate occurring early in the survey questions. The response rate for survey questions 4, 6 and 8 are not reported here because students only responded to these questions when they had answered "yes" to a previous question. Of those who indicated their gender in response to the last question (SQ13), 64\% were male $(n=14)$. Survey results are summarized in Figure 4, which displays both the percent of survey respondents who answered each question and the division of answers among those who responded.

There were three questions on the survey that required a "yes" or "no" answer. These questions are listed in Table 1 along with the percentage of respondents who selected each answer.

Table 1: Survey questions with Yes/No answers

\begin{tabular}{|l|l|r|r|}
\hline SQ\# & Question & \% Yes & \% No \\
\hline 3 & $\begin{array}{l}\text { Have you completed courses that discuss social justice explicitly (using } \\
\text { the term “social justice”) at the Colorado School of Mines? }\end{array}$ & 71 & 29 \\
\hline 5 & $\begin{array}{l}\text { Have you completed courses that discuss social justice-related concepts } \\
\text { at the Colorado School of Mines? }\end{array}$ & 76 & 24 \\
\hline 7 & $\begin{array}{l}\text { Have you learned explicitly about social justice outside of your course } \\
\text { work at the Colorado School of Mines? }\end{array}$ & 44 & 56 \\
\hline
\end{tabular}


An interesting observation from this data is that a higher percentage of students indicated they had learned about social justice from their university courses than from outside experiences. A surprising seventy-one percent of students answered "Yes" to SQ3. This may have been skewed by selection bias, as it is possible that students who had learned about social justice explicitly may have been more inclined to respond to the survey. Also, many of the students may have completed the required first-year course, Nature and Human Values (NHV), which includes social justice. This possibility is discussed further in the "Focus Groups" subsection below.

Three of the survey questions were Likert scale with selections of "very inappropriate (1)," "neutral (3)," "appropriate (4)," and "very appropriate (5)," to determine the extent to which students felt that consideration of social justice was appropriate. A typographical error in the survey eliminated the intended "somewhat inappropriate (2)" response option, so no students selected that option. As shown in Table 2, 81\% of students responded with "very appropriate" or "somewhat appropriate" to "... how appropriate is it for engineering professors to teach social justice concepts in technical engineering courses?” ( $n=16)$. In response to the questions, “... how appropriate is it for professors to teach social justice concepts in non-technical courses?” and “... how appropriate is it for practicing engineers to consider social justice when designing engineering solutions (e.g., designs, systems, models)?,” 87\% of respondents selected either “appropriate” or "very appropriate” ( $n=15)$. Across all three questions, fewer than $20 \%$ of respondents selected a response that did not support the importance of social justice in engineering.

Table 2: Likert-scale survey questions related to appropriateness of social justice in engineering. \%(2) is omitted due to a typographical error in the survey.

\begin{tabular}{|l|l|r|r|r|r|}
\hline SQ\# & Question & $\%(1)$ & $\%(3)$ & $\%(4)$ & $\%(5)$ \\
\hline 9 & $\begin{array}{l}\text { On a scale of 1-5, how appropriate is it for engineering } \\
\text { professors to teach social justice concepts in technical } \\
\text { engineering courses? }\end{array}$ & 13 & 6 & 63 & 19 \\
\hline 10 & $\begin{array}{l}\text { On a scale of 1-5, how appropriate is it for professors to } \\
\text { teach social justice concepts in non-technical courses? }\end{array}$ & 0 & 13 & 47 & 40 \\
\hline 11 & $\begin{array}{l}\text { On a scale of 1-5, how appropriate is it for practicing } \\
\text { engineers to consider social justice when designing } \\
\text { engineering solutions (e.g., designs, systems, models)? }\end{array}$ & 7 & 7 & 27 & 60 \\
\hline
\end{tabular}

The final Likert style question is displayed in Table 3 and included the options "highly irrelevant (1)," "somewhat irrelevant (2)," "neutral (3)," "somewhat relevant (4)," "highly relevant (5)." Eighty percent of the students responded with "highly relevant" or "somewhat relevant," further reinforcing the importance that students placed on this concept.

Table 3: Likert-scale survey question related to relevance of social justice in engineering

\begin{tabular}{|l|l|r|r|r|r|r|}
\hline SQ\# & Question & $\%(1)$ & $\%(2)$ & $\%(3)$ & $\%(4)$ & $\%(5)$ \\
\hline 12 & $\begin{array}{l}\text { On a scale of 1-5, how relevant are social justice } \\
\text { dimensions in engineering practice? }\end{array}$ & 7 & 0 & 13 & 40 & 40 \\
\hline
\end{tabular}


The remaining five survey questions were open-ended. These responses were analyzed based on the themes that emerged through the responses. Each question is addressed separately here.

SQ1. In your own words, please define the term "social justice.”

In response to SQ1, many students described the "who" elements of social justice: i) who is responsible (roughly divided into individuals, communities, or government) and ii) who benefits or loses (individuals and communities). The natural environment was also listed as a beneficiary or loser within some constructs of social justice. Many student responses to SQ1 touched on the concept of equality, with tension between equality of opportunity, equality of outcome, and redressing of past injustices or systemic discrimination. The concept of "fairness" arose in several responses. Some respondents displayed a more concrete view of right vs. wrong, while others indicated that social justice could vary by community context.

In general, the survey responses on the definition of social justice did provide evidence of the students' prior exposure to social justice elements (RQ1). The range of conceptual understandings about social justice from the student survey resembles a range of understandings among those in the engineering and social justice research community, even though the researcher understandings tend to be more robust [1], [7], [15].

SQ2. Envisioning your own future career, what social justice concerns do you anticipate that you will need to consider as you design engineering solutions?

In response to this question, many students identified an element of design decisions that protect from harm, with the object of protection falling into similar categories as SQ1: i.) individuals, ii.) community, or the iii.) environment. A wide variety of attitudes could be inferred from the word choice in the responses. For example, one student seemed to hold a superior attitude:

Most likely, the general public will express negative attitude if the project requires operation within viewing range of residential areas. The uneducated public may also feel fear if a proposed project implements new technology, but they need to understand that we have not done our job as engineers if we do not satisfy the safety criteria of the projects, and their whining is just nonsence $[$ sic]...

while another's wording implied much more of a service-oriented attitude:

I would like to design things that appear simple enough on the surface that anyone could modify them. There is no such thing as being smarter than someone else. Only that you have had access to better education than them. Truly, what I learn does not belong to me. I need to make it as available as I can to everyone and part of that is making things simple to understand.

A few students expressed resistance to the connection between engineering and social justice, with one student answering SQ2 by writing "Little to none. Social justice is a concern for politicians and governments. Not engineers.” This response exemplifies the view of engineering as apolitical, as discussed in the Background section. 
Finally, many students expressed uncertainty, a reasonable response given that they had not yet started their professional careers. This response supports that these students have not learned a great deal about engineering and social justice in their engineering courses. At the same time, these students recognized the importance of social justice in their diverse employment futures; from SQ12, 80\% of surveyed students indicated that social justice dimensions in engineering practice are either relevant (40\%) or highly relevant (40\%).

SQ4. If yes [to SQ3], please list these courses that included social justice as a topic of discussion

SQ6. If yes [to SQ5], please list the names of these courses

Details for SQ4 and SQ6 are omitted here because the answers cannot be discussed without providing institutional information, which would prevent blind review. These details will be provided in the final draft. However, we can disclose that the majority of courses listed were not engineering science core courses.

SQ8. If Yes [to SQ7], please describe where you learned about social justice Students listed television, the Internet, personal observation, life, an internship experience, work, community service, and community college.

\section{Focus Groups}

A wealth of themes related to social justice in control systems engineering emerged from the completion of the four focus groups. This section addresses the themes most closely tied to RQ2 (student perceptions of social justice in IFCS) and the third element of RQ3 (student ability to recognize the social justice dimensions of IFCS).

Students in focus groups selected from both the WI and WOI sections were asked to rate IFCS on a scale of 1-100 with 100 being the most important undergraduate course. Focus group participants from the first WOI section rated the course higher (75-80) than those from the first WI section (50-70). However, the students' explanations for their ratings did not include social justice; instead, they focused on a perception of whether feedback control topics would be useful to their careers. The majority of the students who participated in focus groups were ME majors and many categorized the course as EE despite it being required for both majors. This perception may reflect the disciplines of the instructors, who were primarily affiliated with EE. However, since 12 of 14 focus group participants were MEs, that would not explain the different ratings across WI and WOI sections. The differences across sections are not generalizable due to low sample size (WI $n=7$; WOI $n=7$ ).

Research Question 1. When interpreted narrowly, RQ1 results in a list of classes students noted as including elements of social justice or social impacts of engineering. Within our four focus groups, this list included NHV, Senior Design, Engineering Practices-Introductory Course Sequence (EPICS), Circuits, classes associated with the Humanitarian Engineering minor, and Liberal Arts and International Studies (LAIS) courses in general. 
When interpreted more broadly, RQ1 provides insight into what students learned about social justice in their previous courses. For example, students cited an example from NHV in which a gas station had an off-site buried gas tank that had a 1\% chance of polluting the ground water if not removed; students were asked to discuss the ethical impacts of the engineer's decision either to demand its removal or not. Most of the discussion centered on safety-related social elements. One focus group participant said the IFCS inclusion of social justice really highlighted an omission from previous coursework: "It's kind of eye opening when you think about how much we learn about the money side of engineering. All the classes you have taken, it's weird that we haven't thought about how designs can affect people.” It merits noting that most students had not yet completed their Senior Design sequence, which includes social impacts and may therefore alter this perception.

Research Question 2. RQ2 asks students about their perceptions of control systems classes that sought to explicitly include engineering and social justice units compared to similar classes that do not include social justice. While the WI groups C1 and C2 were asked directly about social justice, the WOI groups A1 and A2 were asked about a related topic that would be more familiar to them: the broader social impacts of engineering. Collectively, the students in the four focus groups responded with agreement on two ideas: they desired i) an increase in integration and ii) a desire for leverage. In brief, the desire for integration reflects that students have identified missing elements in IFCS, and the desire for leverage is the hope that integrating these missing elements assists learning of the core course topics.

Students in the WI groups responded that the actual integration of social justice in IFCS seemed "out of place," and came "from left field." Students had to "change gears" from a familiar mode of cognition in technical courses, e.g., technical thinking, to an unfamiliar mode, e.g., social thinking. They ascribed such social thinking to their humanities and social science courses. These responses seemed in opposition to their expressed desire for integration. However, when asked about their roles in actual engineering practice, all students accentuated the immense importance of considering social justice or social impacts. Students recognized the power that engineers have on social realities. Students also expressed a strong desire to see real-world applications of control systems. In short, they wanted not just to learn the necessary mathematics and abstract theory of feedback control systems, but also to see how the technical applied to contexts in which such systems were used.

In the WI section, explicit efforts were made to include real-world and social justice examples in an integrated manner. Some applications were used multiple times, making them common illustrative reference points throughout the course for students. Yet, WI students expressed that the course lacked integration. This disconnect may be the result of a continuum of abstraction, from highly concrete to highly abstract. What the instructors viewed as concrete, the students viewed as abstract. This is consistent with the literature on novice-expert divides [22].

Students' desire for leverage is directly related to their desire for integration. Students wanted the concrete examples to be used in such a way that those examples helped them learn the abstract technical theory and the mathematics. They wanted the concrete examples to leverage their learning of core technical IFCS principles and theory. It is intriguing how student focus group discussion came full circle: from students expressing not resistance but some discomfort at the integration of social justice or social impacts, to seeing the relevance of social dimensions for 
engineering practice, and to providing ideas on how to integrate such dimensions to maximize learning.

Research Question 3. RQ3 asks how targeted social justice instruction impacts students' plans to pursue additional control systems courses and their abilities to recognize the social justice dimensions of control systems. It should be noted that additional control systems courses are not required for ME or for EE. Students may, however, complete such courses as electives. Overall, only two of the 14 focus group students indicated a desire to electively complete another control system course. Neither student explicitly attributed this desire to the inclusion of social justice issues in the current course.

Reasons for not wanting to complete another course in control system varied. Students who were close to graduation did not have the credit hours remaining to complete additional elective courses. Some students also did not feel that control systems was close enough to their major or minor to take another course. None of the students explicitly connected their desire not to complete another course in control systems to the inclusion of social justice in this course.

Since social justice was not integrated into the WOI section, students in that section were not asked this question explicitly. Students in the WI section felt uncertain as to whether they understood the connection between social justice and control systems; they felt that their experiences had been too limited. However, they were hopeful that this link would be clarified in the final weeks of the course and with the completion of the final project, which included social justice components.

\section{$\underline{\text { Discussion }}$}

Through our examination of our research questions within IFCS, we have found that students have lent insight into how to integrate social justice into engineering courses, into how they prefer to learn, and into a more effective mode of integration and leverage. As noted in the findings for RQ2, the cognitive demands on students to learn technical principles and solve mathematical problems can make it difficult to learn additional course content, especially if students perceive that content will not be tested. This may help explain why students said that their ability to recognize the social justice dimensions in the course was limited.

Students in the WI section were both repelled by and attracted to the integration of engineering and social justice. Some of the rejection of engineering and social justice may have to do with engineering education norms. Students rarely see such integration in other engineering science core courses, so when they do, it appears odd. Also, a tension emerged in the WI students' comments. They recognize how social justice is important in engineering practice, yet also see it as unusual and perhaps out of place in technical engineering education. Despite this response, students indicated that if done in a manner that makes sense to them, the integration of social justice dimensions could have significant learning benefits. Students requested more concrete, tangible examples. This serves as a window of opportunity since there are social justice dimensions of many real-world control systems applications that could be concretely articulated by the instructor. Some students seemed to be saying that if social justice were integrated via these concrete examples, they would see its relevance and value to their learning of IFCS. This 
would help, for instance, the student who said he was just solving math problems but did not actually know what feedback control systems were for the first few months of the course.

To more fully recognize the social justice dimensions of control systems, students may need a gradual scaffold that moves from highly concrete and to more abstract applications that they identify on their own, by being able to:

1) Understand how such systems function in the real world in quite concrete ways (see RQ2 discussion).

2) Be able to identify real-world applications of such systems.

3) Understand how such systems affect society in specific, unique, concrete ways.

4) Begin to recognize the broader social impacts of other such systems.

5) Understand examples of the social justice dimensions of such systems.

6) Be able to identify examples of specific systems and their social justice dimensions.

On top of the already complex technical content and mathematical problems, it may seem as if adding such a gradual scaffold would be detracting from the technical and mathematical learning. Our intention is exactly the opposite: to take students' cues about how they prefer to learn and use the above scaffold to motivate deeper learning of technical concepts and mathematical problem solving. Students clearly conveyed that they do not want to learn technical and mathematical concepts in a vacuum; they want to see real-world applications of control systems and their broader social impacts. As a result, one key instructional goal is to ensure that future students have even more concrete examples; the lead instructor also plans to use two or three real-world, social-justice-relevant applications repeatedly throughout the WI course, so students can see how the theory applies in quite concrete ways to actual feedback control system practice and functionality.

As noted above, student desire for real-world examples of feedback control systems serves as a window of opportunity. Such systems are embedded in social spaces, particularly given the increasing automation pervasive in our everyday lives. Traction control increases safety of our automobiles, increasingly sophisticated HVAC systems improve the safety and comfort of our buildings, controllers for every type of electricity generation from nuclear power plants to wind turbines provide us with extraordinarily reliable electricity, and extensively-controlled satellites provide GPS information at the touch of a finger. It is clear to students that designs related to these engaging systems have social implications, which students can learn to identify after having such identification modeled by their instructor.

However, the key challenge is to identify application examples that are sufficiently concrete in terms of both technical and social elements, while also being sufficiently simple to model with tools learned in this introductory class. For example, while a satellite-positioning controller is well within the realm of the course topics, it may feel too abstract to students who do not think about satellites regularly. Similarly, most of us give little consideration to our electric grid except on the rare occasions when we lose power. Two potentially promising examples that we will pursue and develop throughout the semester are the smart (driverless) car and building HVAC systems. In the case of the smart car, cruise control is a well-accepted example illustrating the meaning of control systems, and the basic modeling of an automobile is within the skillset students should have when completing the course. From a social justice perspective, there are 
concrete safety-related and affordability-related elements to a cruise control system. By following through with this example throughout the semester, we hope to pursue higher levels of abstraction along both the technical and social dimensions while still helping students to leverage the examples in their learning.

\section{Conclusions and Future Work}

The results of this investigation support the assertion that the participating students entered the IFCS course with some knowledge and understanding of social justice and its importance to engineering. Most students, 71\%, had completed a previous course that explicitly included the term social justice. Only 44\% of students had learned about "social justice" outside of their course work. These findings support the importance of including social justice in the engineering curriculum, as exposure outside of the curriculum is low, although it is possible that most of the inclusion is related to just one or two key courses. Further support for this conclusion is provided through the survey's Likert scale questions: most students indicated the social justice was important to their career and should be included in their curriculum.

Analysis of survey and focus group data from two sections of the IFCS course taught during the fall 2014 semester has led to increased understanding of the barriers and opportunities to helping students to understand the social justice implications of their control systems engineering design decisions. Participants report some exposure to social justice explicitly in their education, though focus group discussions often trended more toward social impacts of engineering versus social justice specifically. Focus group responses indicated that students have a desire for integration and a desire for leverage of social justice concepts, understanding the importance of social justice to the engineering profession and hoping that such integration will enhance learning of technical course topics.

Student perceptions of sections of IFCS with and without social justice (or social impacts of engineering) interventions were key topics in focus group discussions. Students in the WI section of IFCS expressed surprise and some discomfort at the integration, partly due to its unfamiliarity in engineering science core courses. However, one also reported appreciation of the eye-opening nature of the integration, which led to questioning of broader curricular foci. Students also indicated that integrating social justice from the outset of the course, and providing the rationale for that integration, would have decreased their discomfort levels and made social justice seem less like an intrusion and more like value added. Focus group participant ratings of the value of the class did not appear correlated with social justice interventions.

The analysis performed for this paper was focused on answering the three primary research questions RQ1-RQ3 and has therefore glossed over other possible themes and avenues for further analysis. We will pursue better understanding of these themes within existing data in the future. In addition, we will use the experience gained during the fall 2014 semester and the data analysis to improve the integration of social justice into IFCS for the fall 2015 course offering. We plan the same instruments for data collection in that semester and hope to gain a deeper understanding while also making a stronger impact on student learning.

In many ways, this study results in more questions than answers for the engineering community. Where is the correct location in the curriculum for the inclusion of social justice? What courses 
best support the importance and urgency of these issues? How can we educators help students to transition smoothly between traditionally "technical" and "social" topics in their courses? How can instructors of engineering science courses best leverage real-world examples and their broader social implications to help students better learn technical concepts?

Note: This paper is part of the session, "Pushing the Boundaries of the Liberal Arts and Engineering: Integrating Social Justice in Engineering Science Courses”

\section{$\underline{\text { Acknowledgments }}$}

This material is based upon work supported by the National Science Foundation under Grant No. EEC-1441806. Any opinions, findings, and conclusions or recommendations expressed in this material are those of the author(s) and do not necessarily reflect the views of the National Science Foundation. We would also like to thank our students for their honest responses to our queries.

\section{$\underline{\text { References }}$}

[1] Riley, Donna, Engineering and Social Justice, San Rafael, CA: Morgan and Claypool Publishers, 2008.

[2] Winner, Langdon, The Whale and the Reactor: A search for limits in an age of high technology, Chicago: The University of Chicago Press, 1988.

[3] Lucena, Juan, Jen Schneider, and Jon Leydens, Engineering and Sustainable Community Development, San Rafael, CA: Morgan \& Claypool Publishers,” 2010.

[4] Adams, Maurianne, Lee Anne Bell, and Pat Griffin (Editors), Teaching for Diversity and Social Justice: A Sourcebook, Routledge, $2^{\text {nd }}$ Ed., 2007.

[5] Edwards, Andrés, The Sustainability Revolution: Portrait of a Paradigm Shift, Gabriola Island, British Columbia: New Society Publishers, 2005.

[6] Downey, Gary, "Are Engineers Losing Control of Technology? From 'Problem Solving' to 'Problem Definition and Solution' in Engineering Education,” Chemical Engineering Research and Design, 83(A6): 583-595, 2005.

[7] Cech, Erin, "The (Mis)framing of social justice: Why ideologies of depoliticization and meritocracy hinder engineers' ability to think about social injustices," in Engineering education for social justice: Critical explorations and opportunities, (ed.) Juan Lucena, New York: Springer, pp. 67-84, 2013.

[8] Lucena, Juan, Defending the Nation: U.S. Policymaking to Create Scientists and Engineers from Sputnik to the 'War against Terrorism' Lanham, MD: University Press of America, 2005.

[9] Downey, Gary, Juan Lucena, Barbara Moskal, Rosamond Parkhurst, Thomas Bigley, Chris Hays, Brent Jesiek, Liam Kelly, Jonson Miller, Sharon Ruff, Jane Lehr, and Amy Nichols-Belo, "The globally-competent engineer: working effectively with people who define problems differently," Journal of Engineering Education, 95(2):107-122, 2006.

[10] Huff, James, "Humanizing Signals and Systems: A Reflective Account," Proceedings of the ASEE Annual Conference, Seattle, WA, 2015.

[11] Riley, Donna, "Engineering Thermodynamics and 21st Century Energy Problems: A Textbook Companion for Student Engagement,” Synthesis Lectures on Engineering, 6(3), 2011, pp. 1-97.

[12] Passino, Kevin, "Scholarship in Engineering for Social Justice: A Practitioner's Forum,"https://hevcp.engineering.osu.edu/. Accessed 3/9/15.

[13] Baille, Caroline, Alice Pawley, and Donna Riley, Engineering and Social Justice, Purdue University Press, 2012. 
[14] Schneider, Jen and Junko Munakata Marr, “Connecting the 'forgotten': Transportation engineering, poverty, and social justice in Sun Valley, Colorado," Engineering education for social justice: Critical explorations and opportunities, (ed.) Juan Lucena, New York: Springer, pp. 67-84, 2013.

[15] Lucena, Juan (Ed), Engineering Education for Social Justice: Critical Explorations and Opportunities, Springer, 2013.

[16] Adams, Robin, Demetra Evangelou, Lyn English, Antonio Dias de Figueiredo, Nicholas Mousoulides, Alice Pawley, Carmen Schifellite, Reed Stevens, Marilla Svinicki, Julie Martin Tenor, and Denise Wilson, "Multiple perspectives on engaging future engineers," Journal of Engineering Education, 100(1): 48-88, 2011.

[17] Schneider, Jen, Juan Lucena, and Jon Leydens, J., "Engineering to help: the value of critique in engineering service,” IEEE Technology and Society Magazine, 28(4): 42-48 2009.

[18] Epprecht, Marc, "Work-study abroad courses in international development studies: some ethical and pedagogical issues,” Canadian Journal of Development Studies, 25(4): 687-706, 2004.

[19] Haws, David, "Ethics instruction in engineering education: a (mini) meta-analysis," Journal of Engineering Education, 90(2):223-229, 2001.

[20] Herkert, Joseph, "Ways of thinking about and teaching ethical problem solving: Microethics and macroethics in engineering," Science and Engineering Ethics, 11:373-385, 2005.

[21] ABET, Criteria for Accediting Engineering Programs, 2011. Available at http://www.abet.org/uploadedFiles/Accreditation/Accreditation_Process/Accreditation_Documents/Cu rrent/eac-criteria-2012-2013.pdf.

[22] Bransford, John, Ann Brown, and Rodney Cocking, Eds., "How Experts Differ from Novices," in How People Learn: Brain, Mind, Experience, and School, Washington, D.C.: National Academy Press, 2000, pp. 29-50.

\section{Appendix A: WOI Section Focus Group Questions}

In the WOI section, we asked:

1. What score on a scale from 1 to 100 with 100 being the most important undergraduate course and 1 being the least important undergraduate course: How would you score this course?

a. Tell us more about that score?

2. What does the phrase "social impacts of engineering" mean?

3. What did you learn in your course, which you did not previously know, regarding the social impacts of engineering?

4. What are some elements of social impacts of engineering that were conveyed by your control systems instructor?

5. What does "social justice” mean?

6. How appropriate is it for engineering professors to teach social justice concepts in technical engineering courses?

7. How appropriate is it for practicing engineers to consider social justice when designing engineering solutions?

8. Tell us about any plans you would have to pursue additional control systems courses. For example: EENG 517 - Theory and Design of Advanced Control Systems, EENG 517 Theory and Design of Advanced Control Systems 


\section{Appendix B: WI Section Focus Group Questions}

In the WI section, we asked

1. What score on a scale from 1 to 100 with 100 being the most important undergraduate course and 1 being the least important undergraduate course: How would you score this course?

a. Tell us more about that score?

2. What does "social justice" mean?

3. What did you learn in your control systems course, which you did not previously know, regarding social justice in engineering?

4. How did your control systems instructor convey the concept of social justice?

5. What does the phrase "social impacts of engineering" mean?

6. What did you learn in your course, which you did not previously know, regarding the social impacts of engineering?

7. What are some elements of social impacts of engineering that were conveyed by your control systems instructor?

8. How appropriate is it for engineering professors to teach social justice concepts in technical engineering courses?

9. How appropriate is it for practicing engineers to consider social justice when designing engineering solutions?

10. What could your instructor have done to better prepare you as an engineer to consider social justice and social impacts to society in engineering?

11. Tell us about any plans you would have to pursue additional control systems courses. For example: EENG 517 - Theory and Design of Advanced Control Systems, EENG 517 Theory and Design of Advanced Control Systems 